Marquette University

e-Publications@Marquette

Exercise Science Faculty Research and

Publications

Exercise Science, Department of

$6-2012$

\title{
Near Infrared Spectroscopic Monitoring During Cardiopulmonary Exercise Testing Detects Anaerobic Threshold
}

Rohit P. Rao

Phoenix Children's Hospital

Michael J. Danduran

Marquette University

J. E. Dixon

Children's Hospital of Wisconsin

Rohit S. Loomba

Medical College of Wisconsin

George M. Hoffman

Medical College of Wisconsin

Follow this and additional works at: https://epublications.marquette.edu/exsci_fac

\section{Recommended Citation}

Rao, Rohit P.; Danduran, Michael J.; Dixon, J. E.; Loomba, Rohit S.; and Hoffman, George M., "Near Infrared Spectroscopic Monitoring During Cardiopulmonary Exercise Testing Detects Anaerobic Threshold" (2012). Exercise Science Faculty Research and Publications. 46.

https://epublications.marquette.edu/exsci_fac/46 


\title{
Near-Infrared Spectroscopic Monitoring During Cardiopulmonary Exercise Testing Detects Anaerobic Threshold
}

\author{
Rohit P. Rao \\ Sections of Cardiology and Critical Care, \\ Phoenix Children's Hospital, \\ Phoenix, AZ \\ Michael J. Danduran
}

Herma Heart Center, Children's Hospital of Wisconsin, Milwaukee, WI

Rohit S. Loomba

Department of Pediatrics, Medical College of Wisconsin, Milwaukee, WI

Jennifer E. Dixon

Herma Heart Center, Children's Hospital of Wisconsin, Milwaukee, WI

George M. Hoffman

Department of Anesthesia, Section of Pediatric Anesthesia, Medical College of Wisconsin, Milwaukee, WI 
NOT THE PUBLISHED VERSION; this is the author's final, peer-reviewed manuscript. The published version may be accessed by following the link in the citation at the bottom of the page.

\begin{abstract}
Cardiopulmonary exercise testing (CPET) provides assessment of the integrative responses involving the pulmonary, cardiovascular, and skeletal muscle systems. Application of exercise testing remains limited to children who are able to understand and cooperate with the exercise protocol. Near-infrared spectroscopy (NIRS) provides a noninvasive, continuous method to monitor regional tissue oxygenation ( $r S O 2)$. Our specific aim was to predict anaerobic threshold (AT) during CPET noninvasively using two-site NIRS monitoring. Achievement of a practical noninvasive technology for estimating AT will increase the compatibility of CPET. Patients without structural or acquired heart disease were eligible for inclusion if they were ordered to undergo CPET by a cardiologist. Data from 51 subjects was analyzed. The ventilatory anaerobic threshold (VAT) was computed on $\mathrm{V}_{\mathrm{CO}_{2}}$ and respiratory quotient post hoc using the standard V-slope method. The inflection points of the regional rSO2 time-series were identified as the noninvasive regional NIRS AT for each of the two monitored regions (cerebral and kidney). AT calculation made using an average of kidney and brain NIRS matched the calculation made by VAT for the same patient. Two-site NIRS monitoring of visceral organs is a predictor of AT.
\end{abstract}

Keywords: NIRS, Cardiopulmonary exercise testing, Anaerobic threshold, Noninvasive monitoring

\title{
Introduction
}

Cardiopulmonary exercise testing (CPET) provides assessment of the integrative responses involving the pulmonary, cardiovascular, and skeletal muscle systems, which are not adequately assessed through the measurement of global or individual organ system function during resting conditions. It is based on the principle that failure typically occurs while the system is under stress. $\underline{6}, \underline{15}$ Nearinfrared spectroscopy (NIRS) provides a noninvasive, continuous method to monitor regional tissue oxygenation ( $\mathrm{rSO} 2) . \underline{10}, \underline{23}$ The use of multisite NIRS monitoring during CPET for the purpose of studying global cardiac output distribution trends, through the patterning of visceral, muscular, and cerebral saturation data in combination with oxygen-consumption data, has been reported in a pilot study. $\underline{17}$ Our specific aim was to predict anaerobic threshold (AT) during CPET noninvasively using two-site NIRS monitoring. The application of exercise testing remains limited to children who are able to understand and cooperate with the exercise protocol and who can tolerate the equipment necessary for measurement of cardiopulmonary responses. Modification of CPET instrumentation by adding complementary technology for those subjects that cannot tolerate some of the

Pediatric Cardiology, Vol 33, No. 5 (June 2012): pg. 791-796. DOI. This article is @ Springer International Publishing AG and permission has been granted for this version to appear in e-Publications@Marquette. Springer International Publishing AG does not grant permission for this article to be further copied/distributed or hosted elsewhere without the express permission from Springer International Publishing AG. 
equipment would open this method of assessment to a wider range of subjects, particularly younger children, thereby conferring significant advantage. Achievement of a practical noninvasive technology for estimating AT will increase the compatibility of CPET for the pediatric population and validate two-site NIRS monitoring for detection of AT during progressive exercise.

\section{Methods}

This study was initiated with funding assistance from the Children's Research Institute, a division of Children's Hospital and Health System and the Medical College of Wisconsin, Milwaukee, WI, with Institutional Review Board approval. Patients without structural or acquired heart disease were eligible for inclusion if they were ordered to undergo CPET by a cardiologist at the Herma Heart Center's Exercise Physiology Laboratory for evaluation of non-life threatening symptoms. The patients underwent a routine physical examination before initiation of the exercise assessment. Consent from parent and assent from subject was obtained before enrollment.

The CPET protocol began with application of 12-lead electrocardiogram (ECG) leads, an automated oscillometric blood pressure cuff on the left arm, and a pulse oximeter on the right index finger (Masimo, Irvine, CA). Two NIRS probes with $4-\mathrm{cm}$ sourcedetector spacing and shallow-field rejection (Adult Somasensor, I NVOS 5100C; Somanetics Corporation, Troy, MI) were placed on the midline forehead and below the 12th rib in the left para vertebral space (rSO2C, rSO-R), respectively. Regional rSO2 was recorded continuously at 1-min intervals at rest, during exercise, and through a 5-min recovery period. Baseline spirometry using a forced expiratory maneuver was performed according to the standards of the American Thoracic Society. Patients were introduced to the treadmill and given specific instructions as to what to expect during the exercise portion of the study. Immediately before the initiation of exercise, a snorkel-style mouthpiece was placed in the child's mouth for the measurement of breath-by-breath oxygen consumption $\left(V_{O_{2}}\right)$, carbon dioxide production $\left(V_{\mathrm{CO}_{2}}\right)$, and instantaneous respiratory quotient (RQ). After $1 \mathrm{~min}$ of baseline data collection, a ramping treadmill protocol was initiated using a standard Bruce protocol on a treadmill ergomater (GE Medical

Pediatric Cardiology, Vol 33, No. 5 (June 2012): pg. 791-796. DOI. This article is @ Springer International Publishing AG and permission has been granted for this version to appear in e-Publications@Marquette. Springer International Publishing AG does not grant permission for this article to be further copied/distributed or hosted elsewhere without the express permission from Springer International Publishing AG. 
Systems, Milwaukee, WI). At set intervals throughout the test, the workload was progressively increased. The progression was terminated when the child reached voluntary or symptom-limited exhaustion (quitting time). Throughout the exercise portion of the test, 12-lead ECG, blood pressure, and $\mathrm{O}_{2}$ saturation, in addition to breath-bybreath ventilatory measures, were recorded every minute. Immediately after exercise, the child was allowed to cool down for 3 min by walking slowly, with the remainder of the 5-min recovery being performed in a seated position. All $S_{p o_{2}}$, heart rate, blood pressure, $\left(V_{\mathrm{O}_{2}}\right), V_{\mathrm{CO}_{2}}, \mathrm{RQ}$, and NIRS data were synchronously aggregated. A test was considered satisfactory if the subject exceeded $90 \%$ of predicted maximum, a plateau occurred in oxygen consumption that did not increase with increasing work, or the RQ was $>1.10$. Subjects who completed the CPET protocol satisfactorily were included in this analysis. Subjects who were unable to complete the CPET protocol or those with incomplete metabolic cart data acquisition were excluded.

The ventilatory anaerobic threshold (VAT) was computed on $V_{\mathrm{CO}_{2}}$ and RQ post hoc using the $\mathrm{V}$-slope method. $\underline{19}$ The absolute twosite data and the change from resting baseline were analyzed using time-series. For each subject, the slope $\Delta \mathrm{rSO} 2 / \mathrm{min}$ was computed for both renal and cerebral beds for the respective aerobic, anaerobic, and recovery periods. The inflection points of the regional rSO2 time-series were identified as the noninvasive regional NIRS anaerobic threshold (NAT) for each of the two monitored regions individually (NAT-rSO2C, NAT-rSO2-R). A composite two-site measure (average NAT) was defined by the average of regional NAT measures. This study used a correlational design with all patients having AT calculated based on NIRS and VAT measurements. AT calculations were performed based on NIRS data from the brain, kidney, and an average of both brain and kidney data in all patients. In addition, VAT-based calculations was also performed for all patients.

\section{Results}

Data from 51 subjects, average age $16.63 \pm 6.81$ years ( 26 male) were used for analysis (Table 1 ). Average exercise time was $13.2 \pm 2.54 \mathrm{~min}$. Data for rSO2-C in one subject was not available due to problems with the probe-skin adhesion. There were no other data

Pediatric Cardiology, Vol 33, No. 5 (June 2012): pg. 791-796. DOI. This article is @ Springer International Publishing AG and permission has been granted for this version to appear in e-Publications@Marquette. Springer International Publishing AG does not grant permission for this article to be further copied/distributed or hosted elsewhere without the express permission from Springer International Publishing AG. 
NOT THE PUBLISHED VERSION; this is the author's final, peer-reviewed manuscript. The published version may be accessed by following the link in the citation at the bottom of the page.

dropouts during the study. The main outcome measures were as follows: (1) AT calculated using NAT brain, NAT kidney, and average of brain and kidney, (2) average NAT, and (3) VAT. Pearson productmoment correlation was used to determine the relationship between the NAT values as well as VAT. In addition, three Bland-Altman plots were constructed to assess the agreement between the NAT and VAT. Mean differences were then calculated by way of subtraction of NAT from VAT, and the limits of agreement (LOAs) were calculated by adding and \pm 2 SD of the mean differences to the mean differences. ${ }^{4} \mathrm{~A}$ p-value $\leq 0.05$ was considered statistically significant. Statistical analysis was performed using SPSS (version 17; SPSS, Chicago, IL) . The Pearson product moment correlation coefficient for average NAT compared with VAT was strong in the positive direction, indicating that an AT calculation made using an average of kidney and brain NIRS matched the calculation made by VAT for the same patient. The Pearson product moment correlation coefficients for kidney NAT and brain NAT compared with VAT both showed moderate correlations, indicating that AT calculations made using only kidney or brain NIRS may not be as close to calculations made by VAT for the same patient (Table 2). The Bland-Altman plots showed a fairly wide range of LOA values: -3.80 to 2.50 for average NAT, -4.29 and 2.26 for brain NAT, and -4.07 and 3.68 for kidney NAT. LOA calculations are listed in Table $\underline{3}$. Mean difference of values, however, was small: -0.65 for average NAT, -1.01 for brain NAT, and -0.20 for kidney NAT. This study is the first to compare NAT and VAT calculations in a series of patients and demonstrates that NIRS tends to underestimate AT compared with VAT. Despite moderate to strong correlations between the measurement methods, there were wide ranges of LOA values as demonstrated by the Bland-Altman plots (Figs. $\underline{1}, \underline{2}, \underline{3}$ ). Distribution of differences in the two measures did not vary between low and high AT values. Mean difference of values, however, was small for all three comparisons. It is thus important for physicians to take into account the underestimation and how it may affect clinical interpretation and decision-making. Average NAT has a greater degree of agreement with VAT and seems to be the most appropriate of those measures assessed by this study for clinical use. Clinical implications of study results will vary in respect to the specific clinical situations. NAT calculation offers a more convenient method of calculation because it is less invasive and thus more comfortable for patients and simpler to

Pediatric Cardiology, Vol 33, No. 5 (June 2012): pg. 791-796. DOI. This article is @ Springer International Publishing AG and permission has been granted for this version to appear in e-Publications@Marquette. Springer International Publishing AG does not grant permission for this article to be further copied/distributed or hosted elsewhere without the express permission from Springer International Publishing AG. 
use for operators. In addition, equipment is readily available and easy to use.

Table 1. Patient demographics

\begin{tabular}{|c|c|}
\hline Age (years) & $16.62 \pm 6.81$ \\
\hline Total no. of patients & 51 \\
\hline Male & 26 \\
\hline Female & 25 \\
\hline Forced vital capacity (L) & $3.85 \pm 1.05$ \\
\hline $\mathrm{FEV}_{1}(\mathrm{~L})$ & $3.37 \pm 0.87$ \\
\hline FVC/FEV $_{1}(\%)$ & $87.56 \pm 7.04$ \\
\hline Exertion time ( $\min )$ & $13.20 \pm 2.54$ \\
\hline Resting heart rate (bpm) & $74.51 \pm 12.58$ \\
\hline Peak heart rate (bpm) & $193.53 \pm 10.11$ \\
\hline Resting systolic blood pressure $(\mathrm{mm} \mathrm{Hg})$ & $110.70 \pm 8.55$ \\
\hline Resting diastolic blood pressure $(\mathrm{mm} \mathrm{Hg})$ & $67.95 \pm 8.35$ \\
\hline Peak systolic blood pressure (mm Hg) & $136.06 \pm 22.20$ \\
\hline Peak diastolic blood pressure $(\mathrm{mm} \mathrm{Hg})$ & $67.95 \pm 8.35$ \\
\hline$V_{\mathrm{O}_{2}}$ peak & $2.64 \pm 0.88$ \\
\hline$P_{V_{2}}$ peak & $102.02 \pm 24.67$ \\
\hline$V_{O_{2}} \mathrm{ml} / \mathrm{kg}$ peak & $43.09 \pm 9.7$ \\
\hline $\mathrm{V}_{\mathrm{CO}_{2}}$ & $0.34 \pm 0.3$ \\
\hline$V_{\mathrm{CO}_{2}}$ peak & $2.96 \pm 1.0$ \\
\hline RQ peak & $1.11 \pm 0.07$ \\
\hline Resting PET $\mathrm{CO}_{2}$ & $36.83 \pm 3.25$ \\
\hline Peak PET CO 2 & $37.74 \pm 5.03$ \\
\hline
\end{tabular}

Table 2. Pearson product-moment correlations between NAT and VAT calculations

Measurement Pearson product-moment correlation coefficient $\quad p$
Average NAT
0.76
$<0.001$
Brain NAT
0.270
0.088
Kidney NAT
0.16
0.277

Table 3. Limits of agreement for Bland-Altman plots for NAT versus VAT calculations

Measurement

Average NAT

\section{Difference (mean \pm SD)}

Pediatric Cardiology, Vol 33, No. 5 (June 2012): pg. 791-796. DOI. This article is @ Springer International Publishing AG and permission has been granted for this version to appear in e-Publications@Marquette. Springer International Publishing AG does not grant permission for this article to be further copied/distributed or hosted elsewhere without the express permission from Springer International Publishing AG. 
NOT THE PUBLISHED VERSION; this is the author's final, peer-reviewed manuscript. The published version may be accessed by following the link in the citation at the bottom of the page.

Measurement

Difference (mean \pm SD)

Brain NAT

$-1.01 \pm 1.67$

Kidney NAT

$-0.20 \pm 1.98$

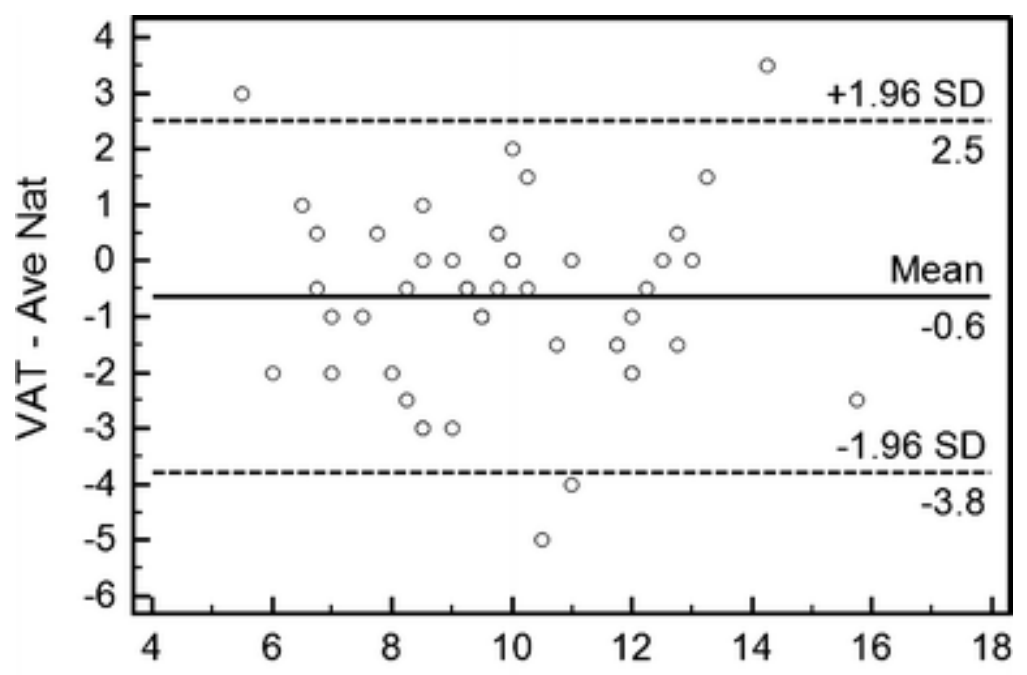

AVERAGE of VAT and Ave Nat

Fig. 1. Bland-Altman plot for average NAT and VAT

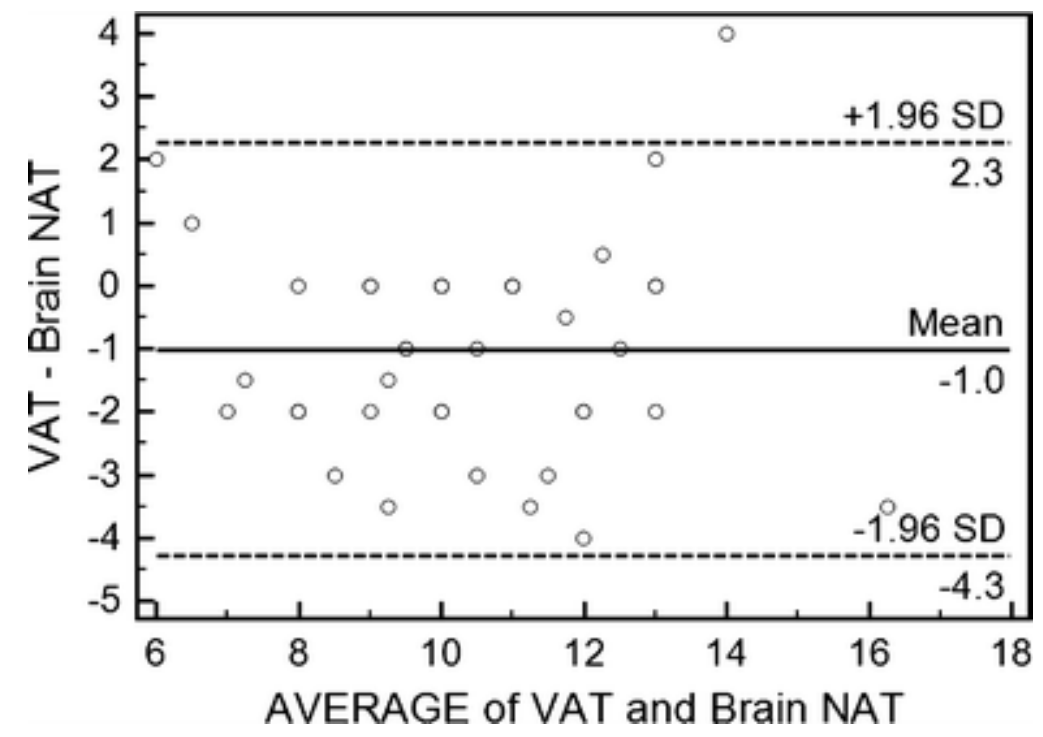

Fig. 2. Bland-Altman plot for brain NAT and VAT

Pediatric Cardiology, Vol 33, No. 5 (June 2012): pg. 791-796. DOI. This article is C Springer International Publishing AG and permission has been granted for this version to appear in e-Publications@Marquette. Springer International Publishing AG does not grant permission for this article to be further copied/distributed or hosted elsewhere without the express permission from Springer International Publishing AG. 
NOT THE PUBLISHED VERSION; this is the author's final, peer-reviewed manuscript. The published version may be accessed by following the link in the citation at the bottom of the page.

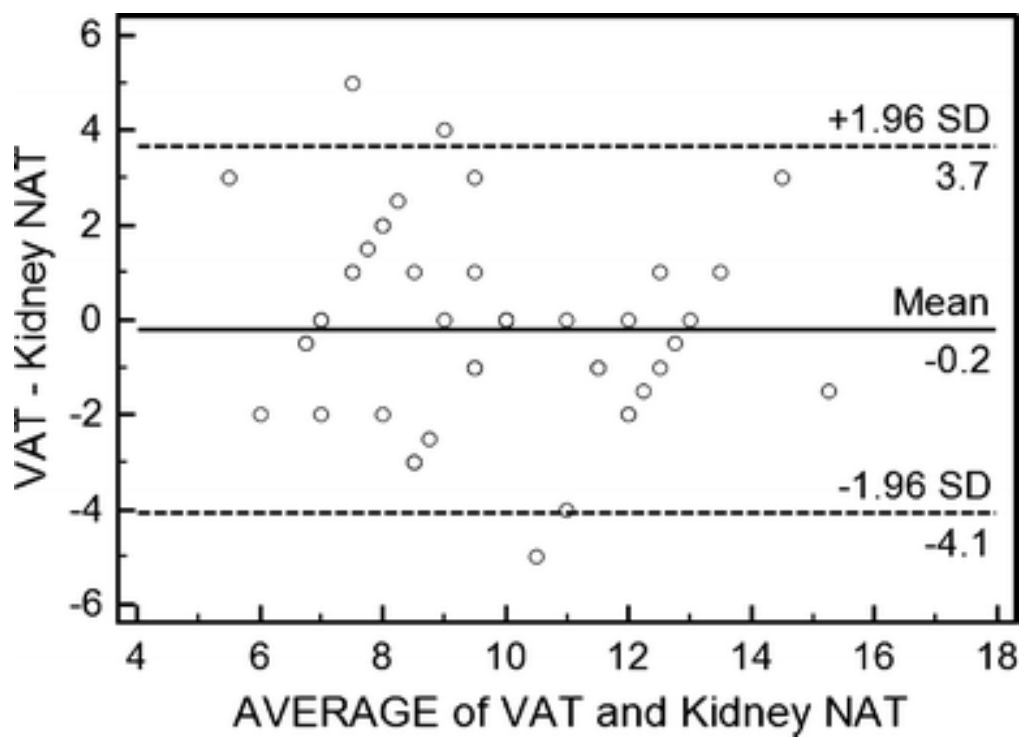

Fig. 3. Bland-Altman plot of kidney NAT and VAT

\section{Discussion}

CPET is used increasingly in a wide spectrum of clinical applications for evaluation of undiagnosed exercise intolerance and for objective determination of functional capacity and impairment. $\underline{1}$ AT has been defined as an intensity of exercise above which an uncoupling of oxygen delivery-to-oxygen consumption relationship is associated with lactate accumulation in the blood, increased carbon dioxide output, and increased ventilatory rate. $\underline{11}, \underline{19}$ Various methods of determining AT have previously been used. The simplest and the most common method used is the V-slope method, which is based on determination of the nonlinear point of increase in slope of carbon dioxide production $\left(V_{\mathrm{CO}_{2}}\right)$ versus oxygen uptake $\left(V_{\mathrm{O}_{2}}\right)$ during incremental exercise. ${ }^{2}$

NIRS devices measure venous-weighted oxyhemoglobin saturation in a field of tissue, rather than in arteries, and thus the rSO2 parameter provides a window into regional oxygen supply-anddemand relationships. The concept of multisite NIRS monitoring to characterize changes in integrative circulatory physiology has been previously described and has been extensively evaluated in the cerebral, $, \underline{8}, \underline{9}, \underline{13}, \underline{21}, \underline{23}, \underline{24}$ splanchnic, $\underline{7}, \underline{16}$ and quasi-global circulations. $\underline{12}, \underline{18}, \underline{22}$ Hoffman et al. used frontal cerebral (rSO2-C) and dorsolateral T10-L2 ( $\mathrm{rSO} 2-\mathrm{R}$ ) renal probe sites to reflect changes in regional oxygenation in circulations presumably under different physiologic control and 
found distinct changes in cerebral and somatic oxygenation during different phases of operation with full flow bypass and selective cerebral perfusion, thus demonstrating the regional nature of $\mathrm{rSO} 2$ measures. NIRS can be used to monitor cerebral and somatic oxygenation in various clinical situations, including during cardiopulmonary bypass, deep hypothermic circulatory arrest, $, \underline{9}, \underline{14}$ and in other high-risk newborns $3, \underline{3}, \underline{20}, \underline{22}, \underline{23}$ and has been found to be helpful in predicting cerebrovascular dysfunction $\underline{13,20}$ and splanchnic ischemia. $\underline{7}$

The use of multisite NIRS monitoring during CPET for the purpose of studying global cardiac output distribution trends, through the patterning of visceral, muscular, and cerebral saturations data in combination with oxygen consumption data, has been reported in a pilot study. $\frac{17}{}$ During exercise, AT is associated with rapid desaturation in nonexercising organs. AT can be estimated at the point of slope change of rSO2-R and $\mathrm{rSO} 2-\mathrm{C}$, as well as the four-site composite measure, during CPET. Using an agreement criterion of 2 min, VAT was best estimated by the four-site average NAT, followed by cerebral and renal NAT. The agreement for arm and leg sites was not good.

This follow-up study showed that two-site NIRS monitoring of visceral organs is a potential predictor of AT. We chose to use the Food and Drug Administration-approved conventional two-site NIRS monitoring technology in CPET. Brain and kidney monitoring sites were chosen for prediction of AT because they represent two poles of circulatory hierarchies and are not directly affected by exercise modality or location of exercising muscle. The trends in somatic regional oxygen saturations showed progressive desaturation with an accelerated slope after AT until exhaustion, which was followed by rapid recovery. By using the data from multiple visceral organs that have been tested in clinical practice, we have described a method of monitoring that should be broadly applicable to different types of exercise. In this study, we have shown that AT can be reliably and accurately estimated by the point of slope change of rSO2-R and rSO2-C during CPET. However, this study also demonstrates that NIRS tends to slightly underestimate AT. Despite moderate to strong correlations between the measurement methods, there were wide ranges of LOA values as demonstrated by the Bland-Altman plots (Figs. $\underline{1}, \underline{2}, \underline{3}$ ). Distribution of differences in the two measures did not vary between low and high AT values. Mean difference of values, 
however, was small for all three comparisons. It is thus important to take into account the underestimation and how it may affect clinical interpretation and decision-making. Average NAT has a greater degree of agreement with VAT and seems to be the most appropriate of those assessed in this study and for clinical use.

Application of exercise testing remains limited to children who are able to cooperate with the examiner and tolerate the equipment necessary for measurement of cardiopulmonary responses. Peak performance is more dependent on the subjects' motivation, especially in children. $\underline{5}, \underline{15}$ Ability of two-site NIRS monitoring to detect AT will resolve this problem and make CPET compatible with a wide range of pediatric age groups. Modification of CPET by adding complementary technology for those subjects who cannot tolerate some of the equipment would confer significant advantage. This type of NIRSguided CPET technology is currently unavailable to children with heart disease and potentially could change the management and follow-up strategies for patients with every form of congenital heart disease.

\section{Limitations}

Limitations of this study include a relatively low number of patients, which leads to greater effects of outlying data points on calculations. Additional patient data may lower mean difference and decrease width of LOA values. This study also demonstrates the low utility of correlation coefficients when assessing agreement between measurement methods. Bland and Altman propose reasons for this, such as the inability of correlations to demonstrate LOA, the need for correlating points to demonstrate a linear relationship rather than showing relation to a line of equality, the effect of range of values on correlation, and the inutility of significance values present in correlations to agreement. 4

\section{Conclusion}

Two-site NIRS monitoring of visceral organs is a predictor of AT. NAT calculations offer a less-invasive alternative to VAT during CPET. Although the LOA between the measures was wide, mean differences were small, and NAT calculations, specifically average NAT, can be

Pediatric Cardiology, Vol 33, No. 5 (June 2012): pg. 791-796. DOI. This article is @ Springer International Publishing AG and permission has been granted for this version to appear in e-Publications@Marquette. Springer International Publishing AG does not grant permission for this article to be further copied/distributed or hosted elsewhere without the express permission from Springer International Publishing AG. 
NOT THE PUBLISHED VERSION; this is the author's final, peer-reviewed manuscript. The published version may be accessed by following the link in the citation at the bottom of the page.

used interchangeably with VAT in situations in which clinical significance of this variance is deemed negligible.

\section{Acknowledgments}

We acknowledge the invaluable logistical support and coordination of this research provided by Mary M. Krolikowski. Grant support came from Pilot Innovative Research Award, Children's Research Institute, Children's Health System, Milwaukee, WI.

\section{References}

${ }^{1}$ Albouaini K, Egred M, Alahmar A, Wright DJ (2007) Cardiopulmonary exercise testing and its application. Postgrad Med J 83:675-682

2Beaver WL, Wasserman K, Whipp BJ (1986) A new method for detecting anaerobic threshold by gas exchange. J Appl Physiol 60:2020-2027

${ }^{3}$ Berens RJ, Stuth EA, Robertson FA et al (2006) Near infrared spectroscopy monitoring during pediatric aortic coarctation repair. Paediatr Anaesth 16: 777-781

${ }^{4}$ Bland J M, Altman DG (1999) Measuring agreement in method comparison studies. Stat Methods Med Res 8: 135-160

${ }^{5}$ Dickstein K, Barvik S, Aarsland T, Snapinn S, Karlsson J (1990) A comparison of methodologies in detection of the anaerobic threshold. Circulation 81: 38-46

${ }^{6}$ ERS Task Force, Palange P, Ward SA et al (2007) Recommendations on the use of exercise testing in clinical practice [see comment]. Eur Respir J 29: 185- 209

${ }^{7}$ Fortune PM, Wagstaff M, Petros AJ (2001) Cerebro-splanchnic oxygenation ratio (CSOR) using near infrared spectroscopy may be able to predict splanchnic ischaemia in neonates. Intensive Care Med 27: 1401-1407

${ }^{8}$ Hayashida M, Kin N, Tomioka T et al (2004) Cerebral ischaemia during cardiac surgery in children detected by combined monitoring of BIS and near-infrared spectroscopy. Br J Anaesth 92:662-669

${ }^{9}$ Hoffman GM, Stuth EA, Jaquiss RD et al (2004) Changes in cerebral and somatic oxygenation during stage 1 palliation of hypoplastic left heart syndrome using continuous regional cerebral perfusion. J Thorac Cardiovasc Surg 127:223-233

${ }^{10}$ Jobsis FF (1977) Noninvasive, infrared monitoring of cerebral and myocardial oxygen sufficiency and circulatory parameters. Science 198: 1264- 1267

${ }^{11}$ Myers J, Ashley E (1997) Dangerous curves. A perspective on exercise, lactate, and the anaerobic threshold. Chest 111:787-795

Pediatric Cardiology, Vol 33, No. 5 (June 2012): pg. 791-796. DOI. This article is @ Springer International Publishing AG and permission has been granted for this version to appear in e-Publications@Marquette. Springer International Publishing AG does not grant permission for this article to be further copied/distributed or hosted elsewhere without the express permission from Springer International Publishing AG. 
NOT THE PUBLISHED VERSION; this is the author's final, peer-reviewed manuscript. The published version may be accessed by following the link in the citation at the bottom of the page.

${ }^{12}$ Nagdyman N, Fleck T, Barth S et al (2004) Relation of cerebral tissue oxygenation index to central venous oxygen saturation in children. Intensive Care Med 30:468-471

${ }^{13}$ Nollert G, J onas RA, Reichart B (2000) Optimizing cerebral oxygenation during cardiac surgery: a review of experimental and clinical investigations with near infrared spectrophotometry. Thorac Cardiovasc Surg 48:247-253

${ }^{14}$ Nollert G, Mohnle P, Tassani-Prell P et al (1995) Postoperative neuropsychological dysfunction and cerebral oxygenation during cardiac surgery. Thorac Cardiovasc Surg 43:260-264

${ }^{15}$ Paridon SM, Alpert BS, Boas SR, Cabrera ME, Caldarera LL, Daniels SR et al (2006) American Heart Association Council on Cardiovascular Disease in the Young, Committee on Atherosclerosis, Hypertension, and Obesity in Youth. Clinical stress testing in the pediatric age group: A statement from the American Heart Association Council on Cardiovascular Disease in the Young, Committee on Atherosclerosis, Hypertension, and Obesity in Youth. Circulation 113: 1905-1920

${ }^{16}$ Petros AJ, Heys R, Tasker RC, Fortune PM, Roberts I, Kiely E (1999) Near infrared spectroscopy can detect changes in splanchnic oxygen delivery in neonates during apnoeic episodes. Eur J Pediatr 158: 173174

${ }^{17}$ Rao RP, Danduran MJ , Frommelt PC et al (2009) Measurement of regional tissue bed venous weighted oximetric trends during exercise by near infrared spectroscopy. Pediatr Cardiol 30:465-471

${ }^{18}$ Schulz G, Weiss M, Bauersfeld $U$ et al (2002) Liver tissue oxygenation as measured by near-infrared spectroscopy in the critically ill child in correlation with central venous oxygen saturation. Intensive Care Med 28: 184- 189

${ }^{19}$ Svedahl K, Maclntosh BR (2003) Anaerobic threshold: the concept and methods of measurement. Can J Appl Physiol 28:299-323

${ }^{20}$ Tsuji M, Saul JP, du Plessis A et al (2000) Cerebral intravascular oxygenation correlates with mean arterial pressure in critically ill premature infants. Pediatrics 106:625-632

${ }^{21}$ Watzman HM, Kurth CD, Montenegro LM, Rome J, Steven J M, Nicolson SC (2000) Arterial and venous contributions to near-infrared cerebral oximetry. Anesthesiology 93: 947-953

${ }^{22}$ Weiss M, Dullenkopf A, Kolarova A, Schulz G, Frey B, Baenziger O (2005) Near-infrared spectroscopic cerebral oxygenation reading in neonates and infants is associated with central venous oxygen saturation. Paediatr Anaesth 15:102-109

${ }^{23}$ Wyatt JS, Cope M, Delpy DT, Wray S, Reynolds EO (1986) Quantification of cerebral oxygenation and haemodynamics in sick newborn infants by near infrared spectrophotometry. Lancet 2: 1063-1066

Pediatric Cardiology, Vol 33, No. 5 (June 2012): pg. 791-796. DOI. This article is @ Springer International Publishing AG and permission has been granted for this version to appear in e-Publications@Marquette. Springer International Publishing AG does not grant permission for this article to be further copied/distributed or hosted elsewhere without the express permission from Springer International Publishing AG. 
NOT THE PUBLISHED VERSION; this is the author's final, peer-reviewed manuscript. The published version may be accessed by following the link in the citation at the bottom of the page.

${ }^{24}$ Yoshitani K, Kawaguchi M, I wata M et al (2005) Comparison of changes in jugular venous bulb oxygen saturation and cerebral oxygen saturation during variations of haemoglobin concentration under propofol and sevoflurane anaesthesia. Br J Anaesth 94:341-346

Pediatric Cardiology, Vol 33, No. 5 (June 2012): pg. 791-796. DOI. This article is C Springer International Publishing AG and permission has been granted for this version to appear in e-Publications@Marquette. Springer International Publishing AG does not grant permission for this article to be further copied/distributed or hosted elsewhere without the express permission from Springer International Publishing AG. 